\title{
Hereditary Thrombophilic Risk Factors for Recurrent Pregnancy Loss
}

\author{
Arseni Markoff ${ }^{*}$, Nadja Bogdanova² and Meyer Michel Samama ${ }^{3}$ \\ ${ }^{1}$ Institute of Medical Biochemistry, ZMBE and IZKF, Münster \\ ${ }^{2}$ Institute of Human Genetics, UKM, Westfalian-Wilhelms University of Munster, Munster, Germany
}

${ }^{3} \mathrm{Hotel}-\mathrm{Dieu}$ University Hospital, Paris, France

\begin{abstract}
This review summarizes current knowledge about the role of hereditary hypercoagulation factors predisposing to thrombophilia-associated recurrent fetal loss. Thrombophilias are a major cause of adverse pregnancy outcome, playing a role in the etiology of up to $40 \%$ of cases worldwide. Hereditary thrombophilic predispositions to recurrent pregnancy wastage include genetic lesions in blood coagulation factors II and $\mathrm{V}$ as well as natural anticoagulants antithrombin, protein $\mathrm{C}$ and protein $\mathrm{S}$. Furthermore, these gene defects confer higher thrombophilia risk in combination. They, as well as the newly described annexin A5 gene M2 promoter allele are associated with repeated fetal loss. The review gives a concise description of the molecular defects arising from the genetic changes, of the role these factors play in the timing and definition of fetal loss, and risk estimates from available studies and meta-analyses. This knowledge is instrumental for a more precise assessment of individual risks for repeated fetal loss and should guide therapeutic strategies, where relevant. Since the average childbearing age increases in western societies, the importance of a timely diagnosis of fetal loss predisposition is increasing.
\end{abstract}

Keywords: Fetal loss; Recurrent pregnancy loss; Thrombophilia; Genetic predisposition; Risk factors

\section{Heritable Thrombophilic Lesions}

Pregnancy loss is a major problem of women's health. About $1 / 5$ of all women worldwide have suffered at least one abortion, and 1/20 have had two or more spontaneous pregnancy losses [1]. More than 500,000 women per year experience a recurrent abortion in the United States of America [2]. Mostly, adverse pregnancy outcome in the first trimester is caused by chromosomal abnormalities incompatible with life. Nevertheless, routine gynecological, endocrine and cytogenetic tests cannot unravel the reason for recurrent fetal losses in $30-40 \%$ of cases [1].

Hereditary or acquired hypercoagulation disorders promoting thrombosis, collectively termed 'thrombophilias', form the molecular basis for the majority of otherwise unexplained fetal loss [3]. Histological studies have demonstrated an increased prevalence of microthrombi in the placental vessels of women with recurrent miscarriage [4,5], although there are some controversies [6]. Normal pregnancies are characterized by a hypercoagulability state that predisposes to thrombosis $[7,8]$. Hereditary thrombophilic defects in combination with these physiological changes may increase the risk of fetal loss [9].

Table 1 gives an overview of inherited defects found in the majority $(70 \%)$ of thrombophilic patients. For two of these defects, the factor V Leiden (FVL) mutation and the prothrombin G20210A mutation (PTm), together accounting for more than half of all cases with inherited thrombophilia, direct DNA analysis is performed when indicated.

It should be noted that the predisposing role of hereditary thrombophilic factors to venous thrombosis has been demonstrated in several clinical studies and associated risks are significant (Table 1). Historically, the predispositions to recurrent fetal loss associated with these lesions have been identified in retrospective analyses of pregnancies (at baseline) of patients included in the European Prospective Cohort on Thrombophilia (EPCOT) study [10]. This analysis demonstrated that women with familial thrombophilia had an increased risk for fetal loss, particularly stillbirth. Later, the data on pregnancy follow-ups were collected from the prospective study and evaluated, which to a great extent confirmed the results obtained previously, namely the increased fetal loss risk, but no conclusions on thromboprophylaxis could be made, because of the small treated patients' number and the varying therapies [11].

The moderate pregnancy loss risk increase in carriers of the hereditary thrombophilic factors known at the time was also concurrent with pregnancy outcomes comparable to the controls. This is why it is necessary for recurrent fetal loss to a) precisely evaluate the role of newly identified hereditary thrombophilia risk factors with higher population incidence, such as M2/ANXA5 and b) check the efficiency of thromboprophylaxis for recurrent pregnancy loss (RPL) patients that are carriers of hereditary thrombophilia lesions in adequately powered and properly controlled clinical trials.

\section{Factor V Leiden}

The factor $\mathrm{V}$ Leiden mutation is an adenine to guanine substitution at position 1691 of the coagulation factor $\mathrm{V}$ gene [12-14]. The resulting amino acid replacement, arginine (R) to glutamine $(\mathrm{Q})$, at position 506 occurs exactly at one of the three contact residues where activated protein $\mathrm{C}$ (APC) would normally cleave and inactivate procoagulant factor Va. As a result, activated factor V Leiden becomes partially resistant to the anticoagulant action of APC and is inactivated at an approximately ten-fold slower rate than normal, thereby resulting in increased thrombin generation and a prothrombotic state.

Factor V Leiden is the most common inherited cause of thrombophilia, being present in heterozygous form in about $12-20 \%$ of patients with venous thrombosis and in $40-50 \%$ of those with recurrent venous thrombosis. The mutation is very common in the white population: about $3 \%$ to $7 \%$ of individuals from northern European

${ }^{*}$ Corresponding author: Arseni Markoff, Institute of Medical Biochemistry, ZMBE, Von Esmarch str. 56, 48149 Münster, E-mail: markoff@uni-muenster.de

Received October 29, 2011; Accepted December 14, 2011; Published december 19,2011

Citation: Markoff A, Bogdanova N, Samama MM (2012) Hereditary Thrombophilic Risk Factors for Recurrent Pregnancy Loss. Hereditary Genetics S1:001. doi:10.4172/2161-1041.S1-001

Copyright: (C) 2012 Markoff A, et al. This is an open-access article distributed under the terms of the Creative Commons Attribution License, which permits unrestricted use, distribution, and reproduction in any medium, provided the original author and source are credited. 
extraction are heterozygous FVL carriers. FVL heterozygosity has been shown to be associated with a 3- to 7 -fold increase of venous thrombosis risk, while homozygotes have a 50- to 100 -fold increased risk [15-17], (Table 1).

An elevated thrombosis risk may be due to a combined defect of factor V Leiden carriage and yet another unequivocally diagnosed risk factor such as homozygosity for MTHFR C677T [17-19].

In a meta-analysis published by Rey et al. [20], factor V Leiden (Table 2) was found to be associated with early and late recurrent fetal loss (OR 2.01, 95\% CI 1.13-3.58) and with late non-recurrent fetal loss (OR 7.83, 95\% CI 2.83-21.67). Upon the exclusion of women with other pathologies that could explain fetal loss, the association between factor $\mathrm{V}$ Leiden and recurrent abortions increased. While protein $\mathrm{S}$ deficiency was related to non-recurrent pregnancy loss occurring after 22 weeks, activated protein $\mathrm{C}$ resistance not due to factor $\mathrm{V}$ Leiden was associated with recurrent early pregnancy loss. In contrast, no significant association was found between protein $\mathrm{C}$ or antithrombin deficiency and recurrent or non-recurrent fetal loss, respectively. Later systematic review of 40 studies confirmed similar associations for FVL (Table 2) and unexplained pregnancy loss [21]. Magnitudes of the observed associations are rather modest and come from case-control studies that tend to overestimate odds ratios, nevertheless they document the role of FVL as a contributing factor to recurrent pregnancy loss. Another trend to overestimate odds ratios comes from inclusion of unrecognized antiphospholipid syndrome (APS) patients in such studies, who have a rather significant risk of fetal losses. A recent systematic review and meta-analysis of systematic prospective trials confirms a small absolute increased risk of late pregnancy loss among FVL carriers (OR 1.52, 95\% CI 0.80-1.25) but excludes association with preeclampsia and fetal growth restriction [22].

\section{APC Resistance Not Related To Factor V Leiden}

APC resistance not associated with factor $\mathrm{V}$ Leiden has been identified as an additional, independent risk factor for deep vein thrombosis [23], and may be an acquired condition resulting from pregnancy [24], and oral contraceptive use [25]. Some laboratory phenotypes such as lupus anticoagulant and high factor VIII levels may be also due to a reduced sensitivity to APC. Reduced APC sensitivity may also be due to other genetic causes including, for example, two mutations affecting the R205 APC cleavage site of factor V [26,27] One mutation (R306T, factor V Cambridge) was indeed causative of APC resistance. The other lesion (R306G) was found in a Hong Kong Chinese and was reported not to be associated with APC resistance.

\section{Factor II PTm}

The 20210G > A mutation (PTm) in the 3' untranslated region of the factor II gene encoding prothrombin causes a gain of function due to an enhanced recognition of the 3' end cleavage signal and increased 3' end processing. This results in accumulation of messenger RNA (prolonged turnover) and greater protein synthesis of prothrombin [28].

Both homozygous and heterozygous carriage of factor $\mathrm{V}$ Leiden or PTm mutations increases the risk of venous thromboembolism (Table 1). The overall prevalence of the prothrombin mutation (PTm) in Europe is approximately $2 \%$. The highest prevalence has been observed in southern Europe (approximately 3\%) and the lowest in the northern parts of the continent (approximately 1.7\%). Heterozygous carriers of the 20210A allele have a 2- to 8-fold increased risk for venous thrombosis [29]. Very few cases of homozygosity for this mutation have been described [30]. Although the severity of the phenotype and the concurrent thrombosis risk would be expected to be higher in the homozygous state, a broad clinical spectrum with striking heterogeneity has emerged in a very small case number [31]. From the meta-analysis [20], there is a significant association found between PTm carriage and recurrent abortion before 13 weeks of pregnancy (OR 2.70, 95\% CI 1.37-5.34) as well as with non-recurrent fetal loss after 20 weeks (Table 2), confirmed in the later systematic review of studies (OR 2.43, 95\% CI 1.12-4.79) [21]. As with FVL, observed RPL associations with PTm are modest and their magnitudes are estimated from case-control

\begin{tabular}{|l|l|l|l|l|}
\hline & \multicolumn{2}{|l|}{ Prevalence in the white population (\%) } & & \\
\hline Thrombophilic defect & Incident VTEa & Recurrent VTE & Normal population & Relative Thrombotic Risk \\
\hline Antithrombin deficiency $[7,8,30]$ & $1-2$ & $2-5$ & $0.02-0.04$ & $5-10$ \\
\hline $\begin{array}{l}\text { Protein C deficiency } \\
{[7,8,30,31]}\end{array}$ & $2-5$ & $5-10$ & $0.2-0.5$ & $6-10$ \\
\hline $\begin{array}{l}\text { Protein S deficiency } \\
{[7,8,30]}\end{array}$ & $1-3$ & $5-10$ & $0.1-1$ & $2-10$ \\
\hline $\begin{array}{l}\text { Factor V Leiden } \\
{[10,11,12]}\end{array}$ & 20 & $40-50$ & $3-7$ & $3-7$ (heterozygotes) \\
\hline $\begin{array}{l}\text { Prothrombin G20210A } \\
{[25,26,27]}\end{array}$ & $3-8$ & $15-20$ & $1-3$ & $50-100$ (homozygotes) \\
\hline
\end{tabular}

a VTE is abbreviated for venous thromboembolism

Table 1:Known hereditary thrombophilia risk factors.

\begin{tabular}{|c|c|c|c|}
\hline Thrombophilic defect & $\begin{array}{l}\text { Recurrent pregnancy loss } \\
\text { before } 13 \text { weeks } \\
(95 \% \mathrm{Cl})\end{array}$ & $\begin{array}{l}\text { Non-recurrent pregnancy } \\
\text { loss } \\
(95 \% \mathrm{Cl})\end{array}$ & $\begin{array}{l}\text { Non-recurrent pregnancy loss } \\
\text { after } 19 \text { weeks } \\
(95 \% \mathrm{Cl})\end{array}$ \\
\hline Antithrombin deficiency & $0.88(0.17-4.48)$ & $1.54(0.97-2.45)$ & $7.63(0.30-196.36)^{\star}$ \\
\hline Protein C deficiency & $1.57(0.23-10.54)$ & $1.41(0.96-2.97)$ & $3.05(0.24-38.51)^{*}$ \\
\hline Protein S deficiency & $14.72(0.99-218)$ & $7.39(1.28-42.83)$ & $20.09(3.70-109-15)^{*}$ \\
\hline Factor V Leiden & $\begin{array}{l}2.01 / 1.91^{*} \\
(1.13-3.58) /(1.01-3.61)^{*}\end{array}$ & $1.73(1.18-2.54)$ & $\begin{array}{l}3.26 / 2.06^{*} \\
(1.82-5.83) /(1.10-3.86)^{*}\end{array}$ \\
\hline Prothrombin G20210A & $\begin{array}{l}2.05 / 2.70^{*} \\
(1.18-3.54) /(1.37-5.35)^{*}\end{array}$ & $2.32(1.12-4.79)$ & $\begin{array}{l}2.30 / 2.66^{*} \\
(1.09-4.87) /(1.28-5.53)^{*}\end{array}$ \\
\hline
\end{tabular}

Table 2: Relative risk for relative fetal loss associated with hereditary thrombophilic defects according to ref. [21] and [22]* 
studies, because of methodological limitations. Nevertheless inherited thrombophilia with the PTm mutation should be considered in the multifaceted pathology of recurrent pregnancy loss.

Individuals carrying both an FVL and a prothrombin G20210A mutation have a 20 -fold increased risk for venous thrombosis, which is higher than for heterozygous carriers of FVL or prothrombin G20210A alone. DNA analysis of both mutations is therefore highly recommended in patients with a personal or family history of thrombosis $[32,33]$. The hereditary deficiencies of anticoagulant proteins antithrombin, protein $\mathrm{C}$ and protein $\mathrm{S}$ are heterogeneous in nature and can be caused by many different genetic lesions [34]. Although they have been the target of intense clinical research, taken together they account for less than $10 \%$ of patients with thrombophilia [35].

The recent systematic review and meta-analysis of systematic prospective trials on pregnancy complications among FVL and PTm carriers excludes the association of PTm carriage with preeclampsia and fetal growth restriction [22].

\section{MTHFR}

It has been suggested that elevated total plasma homocysteine levels (hyperhomocysteinemia) could represent another factor predisposing to thrombosis. Homocysteine is a non-protein-building sulfhydryl amino acid resulting from the intracellular demethylation of methionine. In hepatocytes, homocysteine is remethylated to methionine by the acquisition of a methyl group from methyltetrahydrofolate, derived in a reaction catalyzed by methylentetrahydrofolate reductase (MTHFR). A quite common variant in the MTHFR gene, namely a $\mathrm{C}$ to $\mathrm{T}$ substitution at $\mathrm{CDNA}$ position 677 leading to a change from alanine to valine, may cause increased levels of plasma homocysteine. This variant shows reduced activity at $37^{\circ} \mathrm{C}$ and increased thermolability at $46^{\circ} \mathrm{C}$. Approximately $12 \%$ of the white population is homozygous for the mutation that would cause typical manifestation of moderate hyperhomocysteinemia, when folate levels are at the lower end of the normal range [36]. Although initial data suggested an association between homozygosity for MTHFR C677T and venous thrombosis, prospective studies could not confirm these results $[37,38]$.

A second common polymorphism in the MTHFR gene, A1298C, has been described by van der Put [39]. The prevalence of homozygotes for this variant in the white population is approximately $10 \%$, and $23 \%$ of people are compound heterozygotes for C677T and A1298C [36]. It has been shown that compound heterozygosity for C677T and A1298C, but not homozygosity for A1298C, is associated with increased fasting and post-methionine load homocysteine plasma levels [36].

Over the last fifteen years, a number of studies on the association between inherited thrombophilia and pregnancy loss have been published [40-49]. In view of the somewhat conflicting results of these studies, and because screening tests for thrombophilia become increasingly available, a meta-analysis has been performed on 31 association reports published in the literature [20]. In addition to estimating the actual strength of association between inherited thrombophilia and fetal loss, this meta-analysis also served to clarify whether the associations vary by the timing or definition of fetal loss. The data of this meta-analysis are confirmed and expanded by another systematic review of 40 studies [21] (Table 2). The initial observation that homozygosity for MTHFR C677T could be related to pregnancy loss [50,51], supported by more recent studies [52,53], could not be confirmed, neither in another sample [42], nor by meta-analysis $[20,21]$. The combined carriage of MTHFR polymorphisms C667T or A1298C with FVL or PTm mutation does not seem to increase the risk of fetal losses [21]. On the other hand, results of the Hordaland Homocysteine Study, performed on individuals from the Hordaland country in Western Norway and including over 5800 women analyzed, confirm a doubled risk of placental abruption for C677T homozygotes [54], and possible interaction of C667T with FVL carriage that seems to significantly increase the risk of stillbirth, 3.3-fold [55]. Discrepancies in the studies on the role of $\mathrm{C} 677 \mathrm{~T}$ as a risk factor in pregnancy loss can be partly explained with poorly characterized patient cohorts, specific population and lifestyle determinants, and interactions with unconsidered environmental and genetic factors.

Hyperhomocysteinaemia is a risk factor for placenta-mediated diseases such as pre-eclampsia and placenta abruption as well as for fetal neural-tube defects $[39,51]$. However, it does not appear that homozygosity for MTHFR C667T, the genetic abnormality most commonly associated with hyperhomocysteinemia, is linked to an increased risk of venous thromboembolism (VTE) in pregnant women. As clinical events in homozygotes are likely to reflect the interaction of the genotype with a relative deficiency of vitamins such as B12 and folic acid, the absence of an association of this genotype with gestational VTE may conform to pregnancy-related physiologic reduction in homocysteine levels and/or the effects of folic acid supplements that are now taken widely by women in pregnancy for prevention of neural tube defects. According to the guidelines of the Italian society for Haemostasis and Thrombosis (SISET), evidence of association between pregnancy complications and MTHFR polymorphisms is not sufficient [56]. The use of folic acid is suggested for the whole pregnancy in women with mild hyperhomocysteinemia.

\section{M2 Haplotype of ANXA5}

Annexin A5 (placental anticoagulant protein) occurs in normal placental villi and appears to be reduced when antiphospholipid antibodies are present [57]. Reduced annexin A5 expression in the placental trophoblasts has also been demonstrated immunohistochemically in patients with preeclampsia [58]. Based upon these observations and the reported anticoagulation activity of the protein [59], it has been suggested that annexin A5 molecules form an antithrombotic shield on the apical surface of placental syncytiotrophoblasts that may in pregnancy be disrupted by antiphospholipid antibodies [60]. This hypothesis has received additional support from in vitro studies employing atomic force microscopy and functional assays [61]. Very recent data demonstrate that annexin A5 molecules forming 2D arrays on cellular membranes promote membrane repair and herewith enhance membrane stability [62]. In addition, in a mouse model of atherosclerosis, AnxA5 reduced local vascular and systemic inflammation and vascular remodeling and improved vascular function [63].

A few years ago, we observed that a sequence variation in the promoter of the annexin A5 (ANXA5) gene represents a risk factor for recurrent pregnancy loss [64]. Genomic analysis of a German RPL patient sample, all known to carry neither factor V Leiden nor a prothrombin mutation, revealed an overrepresentation of four consecutive nucleotide substitutions in the ANXA5 promoter, transmitted as a joint haplotype (M2). Reporter gene assays showed that M2 reduces the in vitro activity of the ANXA5 promoter to $37-42 \%$ of the normal level. The possible relationship between M2 and RPL was assessed by comparing RPL patients $(n=70)$ with two independent control groups, namely women from the registry of the Institute of Human Genetics in Münster $(\mathrm{n}=500)$ and from the PopGen biobank 
in Kiel ( $\mathrm{n}=533)$, respectively. Carriers of M2 were found to exhibit a more than two-fold higher RPL risk than non-carriers (OR 2.42, 95\% CI 1.27 - 4.58) in comparison to unselected controls (PopGen), and an almost four-fold higher risk relative to the Münster 'super-controls', i.e. women with successful pregnancies and no previous history of pregnancy loss (OR 3.88, 95\% CI 1.98 - 7.54).

Recently, the expression of ANXA5 in placentas from M2 haplotype carriers has been shown to be reduced by a factor of two at the mRNA level, compared to women lacking M2 [65]. The same study demonstrated that the abundance of placental ANXA5 mRNA in 26 women with obstetric complications (preeclampsia, PE and fetal growth restriction, FGR) was threefold lower than in a control group of seven women without pregnancy complications. Another study confirmed same reduced ANXA5 mRNA levels in placentas of FGR complicated pregnancies [66]. A more recent work communicated that decreased ANXA5 expression in M2/ANXA5 placentas, including such from women with $\mathrm{PE}$ and/or FGR, results of the carriage of the M2 allele, regardless of parental origin [67].

An analysis of the role of M2 in Italian women with repeated fetal loss or pregnancy-related hypertension corroborated the initial findings of the original RPL work [68]. The study reported a similar prevalence of M2 carriers (15\%) in women from Southern Italy as in the German population. In addition, the authors also demonstrated a significant association between M2 carriage and both RPL (defined as three or more fetal losses at $\leq 23$ weeks; OR 3.1, 95\%CI 1.1-9.5) and pregnancy-related hypertensive disorders (OR 2.1, 95\%CI 1.2-3.5). The results of the Italian study also suggested that the role of M2 could be more pronounced in early fetal loss ( $\leq 15$ weeks) than in later events (15 to 23 weeks). This is in contrast to the trend noted for the FVL and PTm thrombophilic mutations, for which the risk of fetal loss increases after the $19^{\text {th }}$ week of pregnancy (Table 2).

A recent work by the same group demonstrated the role of M2/ ANXA5 in pregnancy-related venous thromboembolism, contributing about a three-fold associated risk for this condition [69].

Independent confirmation of the M2/ANXA5 association with recurrent fetal loss was recently obtained in the Japanese population, where carriage of the haplotype results in similar risk as observed for populations of Central Europe, but the population incidence is lower (5,5 vs. $15 \%)$ [70].

Thus, the haplotype M2/ANXA5 appears likely RPL risk factor for European and Asian populations.

M2/ANXA5 is unique as RPL risk factor because of three main reasons:

- high carriage rate among populations of Central Europe, estimated as $15 \%$;

- M2/ANXA5 heterozygtes are at similar RPL risk as FVL and PTm carriers;

- the only thrombophilia related risk factor for comparatively early fetal losses, between gestational weeks (GW) 10 and 15

In the future, it would appear reasonable to study the role of M2 and other ANXA5 haplotypes in various populations and ethnic backgrounds. An additional avenue of further studies could be to clarify the interaction between M2 and other known hereditary RPL risk factors. This notwithstanding, the ANXA5 promoter M2 haplotype undoubtedly represents an established predisposition to fetal loss and should thus be included in the analytical panel of inherited thrombophilic factors. This would not only improve the available prognostic algorithms for RPL, allowing a more precise assessment of individual disease risk, but should also provide a guide to adequate therapies where relevant.

\section{Antiphospholipid Antibodies (aPL) and M2 Haplotype of ANXA5}

The presence of circulating maternal antiphosholipid antibodies is yet another established major risk factor for recurrent pregnancy loss. A higher incidence of RPL has been documented for both low-risk and high-risk pregnancies with aPL [53,71]. Since aPL are a strong risk factor associated with fetal loss, great care should be taken by the selection of RPL patient groups for studies on hereditary thrombophila, as not to include any APS patients. Antiphospholipid antibodies are thought to lead to fetal loss by causing thrombosis of the placental vessels, although the observed variability in placental pathology somehow argues against such a direct involvement $[72,73]$. Lowered expression of ANXA5 in placentas of M2 haplotype carriers [65,67] could be potentially responsible for reduced coverage of phospholipid enriched trophoblast surfaces and hence lead to an increase in the number of exposed available antigenic determinants for generation of aPL. Preliminary results [Cherkelova et al., 2010, unpublished observations] suggest about a twofold higher incidence of M2/ANXA5 in SLE and aPL patients with obstetric complications. The possible predisposition of M2/ANXA5 carriers to develop aPL Abs warrants further studies in larger patient groups.

\section{Conclusive Remarks}

\section{Rising maternal age and growing fetal loss risk}

There is an increasing tendency for childbearing to occur later in women's lives, particularly in Western Europe, Australia, New Zealand, Canada and the United States of America [74]. However, the biologically optimal period for childbearing is between 20 - 35 years of age. After this period, it turns increasingly difficult to fall pregnant and the chances of miscarriage increase with progressing age. This is why it is becoming even more important to diagnose common risk factors and hereditary predispositions to fetal loss in timely fashion. Although data on the combined effect of maternal age and genetic risk factors are still lacking, it is generally expected that the latter would have even stronger bearing on mothers older than 35 . In any case, mothers at later childbearing age should have their fetal loss risk minimized not the least because of the impact of fetal losses on subsequent pregnancies.

\section{Hereditary thrombophilia diagnostics in pregnant women. Evidence of embryonal factors}

It should be noted that hereditary thrombophilic defects have been hitherto known for the majority $(70 \%)$ of hereditary thrombophilia patients. All of these, listed in Table 1, are maternally transmitted lesions. The rest $30 \%$ of heritable thrombophilia are largely unknown and might be due to mutations in proteins auxiliary or co-factory to coagulation cascades. The M2/ANXA5 haplotype is yet another lesion affecting expression levels of the protein with potent anticoagulant function in placenta. Although it cannot be generally responsible for the rest of heritable thrombophilias, it is still a factor to consider when diagnosing the condition. It should also be noted that this defect is conveyed embryonally. Reduced placental expression is observed independent of parental carriage [67], and preliminary analysis demonstrates equal risk for paternal carriers in RPL couples [unpublished results]. 
Based upon our current knowledge, some forms of hereditary thrombophilia, including M2/ANXA5, clearly appear to be associated with RPL. SISET guidelines recommend testing for FVL and PTm in pregnancy [55]. They do not recommend testing for polymorphisms of FXII, MTHFR, and PAI-1 genes, and polymorphisms of FV and FII genes, different from FVL and PTm. It is advisable to perform the screening before pregnancy and if performed during pregnancy, results should be interpreted very carefully and where applicable completed with family history. Genetic testing for the FVL mutation and PTm G20210A variant is indicated for women with RPL or nonrecurrent late miscarriage. Since homocysteine is an established risk factor for obstetric complications, it seems more indicated to dose homocysteine plasma levels than testing for MTHFR polymorphisms. Testing MTHFR A1298C variant could be optional, but its relevance should be judged with caution and only in conjunction with C677T. Evaluation of APC resistance not due to FVL or protein S deficiency, using plasma-based functional assays, is indicated in women with early recurrent abortions whereas women with late miscarriage should be tested for protein $\mathrm{S}$ deficiency alone.

The clinical guidelines for testing for heritable thrombophilia of the British Society for Haematology suggest testing of pregnant women with a family history of venous thrombosis if an event in a first-degree relative was unprovoked, or provoked by pregnancy, combined oral contraceptive exposure or a minor risk factor [75]. The result will be more informative if the first-degree relative has a known thrombophilia.

\section{Anticoagulant therapy in RPL patients with heritable thrombophilia}

A weak recommendation for heritable thrombophilia screening in pregnant women is made at the last American Society of Hematology meeting [76], because available studies do not exclude a beneficial effect of thromboprophylaxis in such patients. Data from clinical trials with anticoagulants (aspirin and low molecular weight heparin, LMWH) in idiopathic recurrent fetal loss are clearly insufficient to draw a justified conclusion about treating women with heritable thrombophilia. A thoroughly conducted trial on thrombophilic patients with a fetal loss, treated with aspirin, vs, aspirin plus LMWH demonstrated beneficial effect of the combined treatment, but lacked a placebo control group [77]. Another recently reported clinical study, the ALIFE trial, was properly controlled with a placebo group but did not report any significant benefit in both treated groups (aspirin and aspirin + LMWH) [78]. Last trial apparently included notable fraction of women with embryonic losses (<wk.10). Both trials were obviously underpowered to address the possibility of improved outcomes among carriers of heritable thrombophilia.

Because of uncertainties associated with the magnitudes of risk concerning heritable thrombophilia and uncertainties on possible benefits of thromboprophylaxis in pregnant women, current American College of Chest Physicians guidelines do not make firm recommendations on the use of antithrombotic therapy in this patient population [79]. These guidelines deleted previous weak recommendations [80], for hereditary thrombophilia screening in women with recurrent fetal loss and for antithrombotic therapy in RPL women with hereditary thrombophilia. The results of ongoing randomized clinical trials are necessary, to prove potential therapeutic efficiency of antithrombotic therapy in women with heritable thrombophillia and recurrent pregnancy loss (Effectiveness of Dalteparin Therapy as Intervention in Recurrent Pregnancy Loss
[http://www.ClinicalTrials.gov; identifier: NCT00400387]; Prevention of Unexplained Recurrent Abortion by Enoxaparine [http://www. ClinicalTrials.gov; identifier: NCT00740545; TIPPS: Thrombophilia in Pregnancy Prophylaxis [http://www.ClinicalTrials.gov; identifier: NCT00967382]).

Noteworthy, individualized VTE risk assessment is recommended in pregnant patients with thrombophilia but no prior venous thrombosis, as opposed to routine pharmacologic prophylaxis. Antepartum clinical surveillance or LMWH/UFH therapy plus postpartum anticoagulants are suggested for thrombophilic women at risk for VTE. The French national recommendations for clinical practice (RPC) under the topic 'prevention of pre-surgical and obstetric VTE', grade the VTE risk for carriage of FVL of PTm mutations as 'moderate' and recommend LMWH/UFH therapy upon antepartum clinical surveillance [81].

\section{Thrombophilic complications in assisted reproductive technology (ART) patients}

Taking in account developments of the last 25 years, including the trend of progressing maternal age with concomitantly growing miscarriage risk in modern societies, it is clear that the use of ART is on the increase. Along with its use, the reports of thromboembolic complications (TEC) resulting in significant maternal morbidity, even mortality, are not rare [82]. TEC associated with ART generally occur as a feature of the ovarian hyperstimulation syndrome (OHSS) by an altogether unclear pathogenic mechanism. On average arterial thrombotic complications (ATC) are present earlier in in vitro fertilization (IVF) pregnancies and are almost always concurrent with OHSS symptoms development. In contrast, venous thrombotic complications (VTC) occur later, days to weeks after the resolution of OHSS. Although the true incidence of ATC and VTC resulting from ART is difficult to establish from the literature, it is clear from available reports that inherited thrombophilia has been detected in altogether $1 / 3$ of the women tested, with $41 \%$ prevalence in the VTC vs. $19 \%$ in the ATC group [82]. Much research remains to be done to minimize the potentially devastating effects of TEC in IVF pregnancies, but testing for inherited thrombophilia might be an indication in ART.

\section{M2/ANXA5 diagnostics and questions of therapy in RPL patients}

Genotyping analyses of RPL cohorts from Central Europe (German, Italian and French) demonstrate incidence of the M2 haplotype in $24-$ $34 \%$ of the patients, depending on the strength of the selection criterion ( $\geq 2$, vs. $\geq 3$ losses). In contrast, the incidence of the marker in the general Central European population is $15 \%$, so the calculated relative risk for RPL carriers is between 2.5 and 3. Since this risk is very similar to the relative risks contributed by the 'classic' thrombophilia factors, PTm and FVL and the incidence of M2 in the general population is 3 5 fold higher, genetic testing should be recommended for women with comparatively early $(10-15 \mathrm{GW})$ unexplained recurrent pregnancy losses, or pregnant women with unexplained VTE.

Taken the possibility that M2 carriage might be a predisposing factor for aPL Abs development, a treatment with anticoagulants that has proven successful in obstetric APS syndrome might be applicable at least to a subset of M2 carriers suffering RPL.

The possible therapeutic relevance of LMWH therapy in M2 carriers should be evaluated from maximum patient resources enrolled in completed and ongoing clinical trials to reach the necessary statistical power and because of the difficulties in obtaining sponsorship and organizing new trials with the necessary cohorts size. 


\section{Acknowledgements}

The authors are grateful to JC Gris, CHU Nimes, for critically reading the manuscript.

\section{References}

1. Branch DW, Silver RM, Blackwell JL, Blackwell JL, Reading JC, et al. (1992) Outcome of treated pregnancies in women with antiphospholipid syndrome: an update of the Utah experience. Obstet Gynecol 80: 614-620.

2. Bick RL (2000) Recurrent miscarriage syndrome due to blood coagulation protein/platelet defects: prevalence, treatment and outcome results. DRW Metroplex Recurrent Miscarriage Syndrome Cooperative Group. Clin Appl Thromb Hemost 6: 115-125.

3. Kupferminc MJ, Eldor A, Steinman A, Many A, Bar-Am A, et al. (1999) Increased frequency of genetic thrombophilia in women with complications of pregnancy. N Engl J Med 340: 50-52.

4. Out HJ, Kooijman CD, Bruinse HW, Derksen RH (1991) Histopathological findings in placentae from patients with intra-uterine fetal death and antiphospholipid antibodies. Eur J Obstet Gynecol Reprod Biol 41: 179-186.

5. Rai R, Regan L, Hadley E, Dave M, Cohen H (1996) Second-trimester pregnancy loss is associated with activated protein $\mathrm{C}$ resistance. $\mathrm{Br} \mathrm{J}$ Haematol 92: $489-490$

6. Alfirevic Z, Kurjak A (1990) Transvaginal colour Doppler ultrasound in normal and abnormal early pregnancy. J Perinat Med 18: 173-180.

7. Sanson BJ, Simioni P, Tormene D, Moia M, Friederich PW, et al. (1999) The incidence of venous thromboembolism in asymptomatic carriers of a deficiency of antithrombin, protein C, or protein S: a prospective cohort study. Blood 94: 3702-3706.

8. Simioni P. Sanson BJ, Brandoni P, Tormene D, Friederich PW, et al. (1999) Incidence of venous thromboembolism in families with inherited thrombophilia. Thromb Haemost 81: 198-202.

9. Kupferminc MJ (2003) Thrombophilia and pregnancy. Reprod Biol Endocrino 1: 111.

10. Preston FE, Rosendaal FR, Walker ID, Briët E, Berntorp E, et al. (1996) Increased fetal loss in women with heritable thrombophilia. Lancet 348:913916.

11. Vossen CY, Preston FE, Conard J, Fontcuberta J, Makris M, et al. (2004) Hereditary thrombophilia and fetal loss: a prospective follow-up study. J Thromb Haemost 2: 592-596.

12. Bertina RM, Koeleman BP, Koster T, Rosendaal FR, Dirven RJ, et al. (1994) Mutation in blood coagulation factor $\mathrm{V}$ associated with resistance to activated protein C. Nature 369:64-67.

13. Greengard JS, Sun X, Xu X, Fernandez JA, Griffin JH, et al. (1994) Activated protein $\mathrm{C}$ resistance caused by Arg506GIn mutation in factor Va. Lancet 343 : 1361-1362.

14. Voorberg J, Roelse J, Koopman R, Büller H, Berends F, et al. (1994) Association of idiopathic venous thromboembolism with single point-mutation at Arg506 of factor V. Lancet 343: 1535-1536.

15. Griffin JH, Evatt B, Wideman C, Fernandez JA (1993) Anticoagulant protein C pathway defective in majority of thrombophilic patients. Blood 82: 1989-1993.

16. Koster T, Rosendaal FR, de Ronde H, Briet E, Vandenvroucke JP, et al. (1993) Venous thrombosis due to poor anticoagulant response to activated protein $\mathrm{C}$ : Leiden thrombophilia study. Lancet 342: 1503-1506.

17. Ridker PM, Hennekens CH, Selhub J, Miletich JP, Malinow MR, et al. (1997) Interrelation of hyperhomocyst(e)inemia, factor $\mathrm{V}$ Leiden, and risk of future venous thromboembolism. Circulation 95: 1777-1782.

18. Cattaneo M, Tsai MY, Bucciarelli P, Taioli E, Zighetti ML, et al. (1997) A common mutation in the methylenetetrahydrofolate reductase gene (C677T) increases the risk for deep-vein thrombosis in patients with mutant factor $V$ (factor V:Q506). Arterioscler Thromb Vasc Biol 17: 1662-1666.

19. Eldibany MM, Caprini JA (2007) Hyperhomocysteinemia and thrombosis: an overview. Arch Pathol Lab Med 131: 872-884.

20. Rey E, Kahn SR, David M, Shrier I (2003) Thrombophilic disorders and fetal loss: a meta-analysis. Lancet 361: 901-908.
21. Robertson L, Wu O, Langhorne P, Twaddle S, Clark P, et al. (2006) Thrombophilia in pregnancy: a systematic review. Br J Haematol 132: 171-196.

22. Rodger MA, Betancourt MT, Clark P, Lindqvist PG, Dizon-Townson D, et al (2010) The association of factor $V$ Leiden and prothrombin gene mutation and placenta-mediated pregnancy complications: a systematic review and metaanalysis of prospective cohort studies. PLoS Med 7: e1000292.

23. de Visser MC, Rosendaal FR, Bertina RM (1999) A reduced sensitivity for activated protein $\mathrm{C}$ in the absence of factor $\mathrm{V}$ Leiden increases the risk of venous thrombosis. Blood 93: 1271-1276.

24. Cumming AM, Tait RC, Fildes S, Yoong A, Keeney S, et al. (1995) Development of resistance to activated protein $\mathrm{C}$ during pregnancy. $\mathrm{Br} \mathrm{J}$ Haematol 90: 725727.

25. Olivieri O, Friso S, Manzato F, Guella A, Bernardi F, et al. (1995) Resistance to activated protein $\mathrm{C}$ in healthy women taking oral contraceptives. $\mathrm{Br} \mathrm{J}$ Haematol 91: $465-470$

26. Chan WP, Lee CK, Kwong YL, Lam CK, Liang R (1998) A novel mutation of $\mathrm{Arg}^{306}$ of factor $\mathrm{V}$ genein Hong Kong Chinese. Blood 91: 1135-1139.

27. Williamson D, Brown K, Luddington R, Baglin C, Baglin T (1998) Factor $\mathrm{V}$ Cambridge. A new mutation $\left(\mathrm{Arg}^{306} \rightarrow \mathrm{Thr}\right.$ ) associated with resistance to activated protein C. Blood 91: 1140-1144.

28. Gehring NH, Frede U, Neu-Yilik G, Hundsdoerfer P, Vetter B, et al. (2001) Increased efficiency of mRNA 3' end formation: a new genetic mechanism contributing to hereditary thrombophilia. Nat Genet 28: 389-392.

29. Poort SR, Rosendaal FR, Reitsma PH, Bertina RM (1996) A common genetic variation in the 3'-untranslated region of the prothrombin gene is associated with elevated plasma prothrombin levels and an increase in venous thrombosis. Blood 88: 3698-3703

30. Rosendaal FR, Doggen CJ, Zivelin A, Arruda VR, Aiach M et al. (1998) Geographic distribution of the $20210 \mathrm{G}$ to A prothrombin variant. Thromb Haemost 79: 706-708

31. Bosler D, Mattson J, Crisan D (2006) Phenotypic heterogeneity in patients with homozygous Prothrombin 20210AA genotype. J Mol Diagn 8: 420-425.

32. McGlennen RC, Key NS (2002) Clinical and laboratory management of the prothrombin G20210A mutation. Arch Pathol Lab Med 126: 1319-1325.

33. Press RD, Bauer KA, Kujovich JL Heit JA (2002) Clinical utility of factor V leiden (R506Q) testing for the diagnosis and management of thromboembolic disorders. Arch Pathol Lab Med 126: 1304-1318.

34. Seligsohn U, Lubetsky A (2001) Genetic susceptibility to venous thrombosis. N Engl J Med 344: 1222-1231.

35. Florell SR, Rodgers GM 3rd (1996) Utilization of testing for activated protein C resistance in a reference laboratory. Am J Clin Pathol 106: 248-252.

36. Hanson NQ, Aras O, Yang F, Tsai MY (2001) C677T and A1298C polymorphisms of the methylenetetrahydrofolate reductase gene: incidence and effect of combined genotypes on plasma fasting and post-methionine load homocysteine in vascular disease. Clin Chem 47: 661-666.

37. Cattaneo M (1999) Hyperhomocysteinemia, atherosclerosis and thrombosis Thromb Haemost 81: 165-176.

38. Tsai AW, Cushman M, Tsai MY (2001) Serum homocysteine, MTHFR C677T genotype and risk of venous thromboembolism: the LITE study. Thromb Haemost 85: 324a.

39. van der Put NML, Gabreels F, Stevens EMB, Smetink JATrijbels FJ, Eskes TK, et al. (1998) A second common mutation in the methylentetrahydrofolate reductase gene: an additional risk factor for neural-tube defects? Am J Hum Genet 62: 1044-1051.

40. Brenner B, Sarig G, Weiner Z, Younis J, Blumenfeld Z, et al.(1999) Thrombophilic Polymorphisms are common in women with fetal loss without apparent cause. Thromb Haemost 82: 6-9.

41. Finan RR, Tamim H, Ameen G, Sharida HE, Rashid M, et al. (2002) Prevalence of factor V G1691A (factor V-Leiden) and prothrombin G20210A gene mutations in a recurrent miscarriage population. Am J Hematol 71: 300-305.

42. Foka ZJ, Lambropoulos AF, Saravelos H, Karas GB, Karavida A, et al (2000) Factor V Leiden and prothrombin G20210A mutations, but no 
methylenetetrahydrofolate reductase $\mathrm{C} 677 \mathrm{~T}$, are associated with recurrent miscarriages. Hum Reprod 15: 458-462.

43. Kovalevsky G, Gracia CR, Berlin JA, Sammel MD, Barnhart KT (2004) Evaluation of the association between hereditary thrombophilias and recurrent pregnancy loss: a meta-analysis. Arch Intern Med 164: 558-563.

44. Pihusch R, Buchholz T, Lohse $\mathrm{P}$, Rübsamen $\mathrm{H}$, Rogenhofer $\mathrm{N}$, et al (2001) Thrombophilic gene mutations and recurrent spontaneous abortion: prothrombin mutation increases the risk in the first trimester. Am J Reprod Immunol 46: 124-131.

45. Reznikoff-Etiévan MF, Cayol V, Carbonne B, Robert A, Coulet F, et al. (2001) Factor $\mathrm{V}$ Leiden and $\mathrm{G} 20210 \mathrm{~A}$ prothrombin mutations are risk factors for very early recurrent miscarriage. BJOG 108: 1251-1254

46. Ridker PM, Miletich JP, Buring JE, Ariyo AA, Price DT, et al. (1998) Factor V Leiden mutation as a risk factor for recurrent pregnancy loss. Ann Intern Med 128: $1000-1003$

47. Sarig G, Younis JS, Hoffman R, Lanir N, Blumenfeld Z, et al. (2002) Thrombophilia is common in women with idiopathic pregnancy loss and is associated with late pregnancy wastage. Fertil Steril 77: 342-347.

48. Wramsby ML, Sten-Linder M, Bremme K (2000) Primary habitual abortions are associated with high frequency of factor $\mathrm{V}$ Leiden mutation. Fertil Steril 74 : 987-991.

49. Younis JS, Brenner B, Ohel G, Tal J, Lanir N, et al. (2000) Activated protein C resistance and factor $\mathrm{V}$ Leiden mutation can be associated with first- as well as second-trimester recurrent pregnancy loss. Am J Reprod Immunol 43: 31-35.

50. Nelen WL, Blom HJ, Steegers EA, den Heijer M, Eskes TK (2000) Hyperhomocysteinemia and recurrent early pregnancy loss: a meta-analysis. Fertil Steril 74: 1196-1199.

51. van der Molen EF, Arends GE, van der Put NJ, Heil SG, Eskes TK, et al. (2000) A common mutation in the 5,10-methylenetetrahydrofolate reductase gene as a new risk factor for placental vasculopathy. Am J Obstet Gynecol 182:12581263.

52. Goodman CS, Coulam CB, Jeyendran RS, Acosta VA, Roussev R (2006) Which thrombophilic gene mutations are risk factors for recurrent pregnancy loss? Am J Reprod Immunol 56: 230-236.

53. Subrt I, Ulvova-Gallova Z, Bibkova K, Micanova Z, Hejnalova M, et al. (2008) Recurrent pregnancy loss and frequency of eight antiphospholipid antibodies and genetic thrombophilic factors in Czech women. Am J Reprod Immunol 59: 193-200.

54. Nurk E, Tell GS, Refsum H, Ueland PM, Vollset SE (2004) Associations between maternal methylenetetrahydrofolate reductase polymorphisms and adverse outcomes of pregnancy: the Hordaland Homocysteine Study. Am J Med 117:26-31.

55. Nurk E, Tell GS, Refsum H, Ueland PM, Vollset SE (2006) Factor V Leiden, pregnancy complications and adverse outcomes: the Hordaland Homocysteine Study. QJM 99:289-298.

56. Lussana F, Dentali F, Abbate R d'Aloja E, D'Angelo A, et al. (2009) Screening for thrombophilia and antithrombotic prophylaxis in pregnancy: Guidelines of the Italian Society for Haemostasis and Thrombosis (SISET). Thromb Res 124: e19-e25.

57. Rand JH, Wu XX, Guller S, Gil J, Guha A, et al. (1994) Reduction of annexin-V (placental anticoagulant protein-I) on placental villi of women with antiphospholipid antibodies and recurrent spontaneous abortion. Am J Obstet Gynecol 171: 1566-1572.

58. Shu F, Sugimura M, Kanayama N, Kobayashi H, Kobayashi T, et al. (2000) Immunohistochemical study of annexin $\mathrm{V}$ expression in placentae of preeclampsia. Gynecol Obstet Invest 49: 17-23.

59. Romisch J, Seiffge D, Reiner G, Paques EP, Heimburger N (1991) In-vivo antithrombotic potency of placenta protein 4 (annexin V). Thromb Res 61: 93104

60. Rand JH, Wu XX (1999) Antibody-mediated disruption of the annexin-V antithrombotic shield: a new mechanism for thrombosis in the antiphospholipid syndrome. Thromb Haemost 82: 649-655.

61. Rand JH, Wu XX, Quinn AS, Chen PP, McCrae KR, et al. (2003) Human monoclonal antiphospholipid antibodies disrupt the annexin A5 anticoagulant crystal shield on phospholipid bilayers: evidence from atomic force microscopy and functional assay. Am J Pathol 163: 1193-2000.

62. Bouter A, Gounou C, Bérat R, Tan S, Gallois B, et al. (2011) Annexin-A5 assembled into two-dimensional arrays promotes cell membrane repair. Nat Commun 2:270.
63. Ewing MM, de Vries MR, Nordzell M, Pettersson K, de Boer HC, et al. (2011) Annexin A5 therapy attenuates vascular inflammation and remodeling and improves endothelial function in mice. Arterioscler Thromb Vasc Biol 31:95101

64. Bogdanova N, Horst J, Chlystun M, Croucher PJ, Nebel A, et al. (2007) A common haplotype of the annexin A5 (ANXA5) gene promoter is associated with recurrent pregnancy loss. Hum Mol Genet 16: 573-578.

65. Chinni E, Tiscia GL, Colaizzo D, Vergura P, Margaglione M, et al. (2010) Expression in human placenta is influenced by the carriage of the common haplotype M2. Fertil Steril 91: 940-942.

66. Sifakis S, Soufla G, Koukoura O, Soulitzis N, Koutroulakis D, et al. (2010) Decreased annexin A5 mRNA placental expression in pregnancies complicated by fetal growth restriction. Thromb Res 125: 326-331.

67. Markoff A, Gerdes S, Feldner S, Bogdanova N, Gerke V, et al. (2010) Reduced allele specific annexin A5 mRNA levels in placentas carrying the M2/ANXA5 allele. Placenta 31: 937-940.

68. Tiscia G, Colaizzo D, Chinni E, Pisanelli D, Sciannamè N, et al. (2009) Haplotype M2 in the annexin A5 (ANXA5) gene and the occurrence of obstetric complications. Thromb Haemost 102: 309-313.

69. Grandone E, Tiscia G, Colaizzo D, Chinni E, Pisanelli D, et al. (2010) Role of the M2 haplotype within the annexin A5 gene in the occurrence of pregnancyrelated venous thromboembolism. Am J Obstet Gynecol 203: 461.e1-e5.

70. Miyamura H, Nishizawa H, Ota S, Suzuki M, Inagaki A, et al. (2011) Polymorphisms in the annexin A5 gene promoter in Japanese women with recurrent pregnancy loss. Mol Hum Reprod 17:447-452.

71. Empson M, Lassere M, Craig JC, Scott JR (2002) Recurrent pregnancy loss with antiphospholipid antibody: A systematic review of therapeutic trials. Obstet Gynecol 99: 135-144.

72. Nilsson I, Astedt B, Hedner U, Berezin D (1975) Intrauterine death and circulating anticoagulant ("antithromboplastin"). Acta Med Scand 197: 153-159.

73. Salafia CM, Cowchock FS (1997) Placental pathology and antiphospholipid antibodies: A descriptive study. Am J Perinat 14: 435-441.

74. Royal College of Obstetricians and Gynecologists RCOG (2009) RCOG Statement on later maternal age. http://www.rcog.org.uk/what-we-do/ campaigning-and-opinions/statement/rcog-statement-later-maternal-age Accessed 10 Oct 2010

75. Baglin T, Gray E, Greaves M, Hunt BJ, Keeling D, et al. (2010) Clinica guidelines for testing for heritable thrombophilia. Br J Haematol 149: 209-220.

76. Bates SM (2010) Consultative Hematology: The Pregnant Patient Pregnancy Loss. Hematology Am Soc Hematol Educ Program 2010: 166-172.

77. Gris JC, Mercier E, Quéré I, Lavigne-Lissalde G, Cochery-Nouvellon E, et al (2004) Low-molecular-weight heparin versus low-dose aspirin in women with one fetal loss and a constitutional thrombophilic disorder. Blood 103: 36953699.

78. Kaandorp SP, Goddijn M, van der Post JA, Hutten BA, Verhoeve HR, et al. (2010) Aspirin plus heparin or aspirin alone in women with recurrent miscarriage. N Engl J Med 362: 1586-1596.

79. Bates SM, Greer IA, Pabinger I, Sofaer S, Hirsh J (2008) Venous thromboembolism, thrombophilia, antithrombotic therapy, and pregnancy: American College of Chest Physicians Evidence-Based Clinical Practice Guidelines (8th Edition). Chest 133: 844S-886S

80. Blickstein D, American College of Chest Physicians (2006) The Seventh American College of Chest Physicians Guidelines for the antenatal and peripartum management of thrombophilia: A tutorial. Obstet Gynecol Clin North Am 33: 499-505.

81. Samama CM (2005) Prévention de la maladie thromboembolique veineuse périopératoire et obstréticale. Sang Thromb Vaisseaux 17: 439-467.

82. Chan WS, Dixon ME (2008) The "ART" of thromboembolism: A review of assisted reproductive technology and thromboembolic complications. Thromb Res 121: 713-726.

This article was originally published in a special issue, Hereditary Disorder handled by Editor(s). Dr. X. Long Zheng, University of Pennsylvania, USA 